\title{
Eisenmenger Syndrome: Not Always Inoperable
}

\author{
Jing-Bin Huang MD, Jian Liang MD, and Li-Yan Zhou MD
}

\author{
Introduction \\ Pathophysiology \\ Treatment of Eisenmenger Syndrome \\ Corrective Interventions \\ Future Directions \\ Conclusions
}

\begin{abstract}
Recently, advanced therapies for pulmonary arterial hypertension have become available, and have been effective in reducing pulmonary vascular resistance and symptoms in patients with Eisenmenger syndrome, previously thought to be inoperable. This review summarizes the current knowledge on the pathophysiology and treatment of Eisenmenger syndrome. The recent introduction of targeted therapies in pulmonary arterial hypertension has led to a renewed insight in the pathophysiology and treatment of Eisenmenger syndrome. Patients with Eisenmenger syndrome using a diagnostic-treatment-and-repair strategy are amenable to surgery after successful treatment with advanced therapy. With continued improvements in the diagnosis, preoperative management, refinement of surgical techniques and intra- and postoperative management strategies, the patients with Eisenmenger syndrome selected using a diagnostic-treatment-and-repair strategy are operable with safety and efficacy in the current era with advanced pulmonary arterial hypertension therapy. Future directions of Eisenmenger syndrome may be the combination of reversal of pulmonary vascular remodeling and correction. Key words: Eisenmenger syndrome; operable; pulmonary arterial hypertension. [Respir Care 2012;57(9):1488-1495. () 2012 Daedalus Enterprises]
\end{abstract}

\section{Introduction}

Eisenmenger syndrome is defined as a congenital heart defect that initially causes a major left-to-right shunt, in-

Drs Huang and Liang are affiliated with the Department of Cardiothoracic Surgery, Affiliated Ruikang Hospital of Guangxi Traditional Chinese Medical College, Nanning, Guangxi Zhuang Autonomous Region, China. Dr Zhou is affiliated with the Department of Hepatobiliary Surgery, PLA Hospital, Beijing, China.

This study was partly supported by grant RKZ201001 from the Ruikang Hospital Natural Science Foundation. The authors have disclosed no conflicts of interest.

Correspondence: Jing-Bin Huang MD, Department of Cardiothoracic Surgery, Affiliated Ruikang Hospital of Guangxi Traditional Chinese Medical College, 10 Huadong Road, 530011, Nanning, Guangxi Zhuang Autonomous Region, China. E-mail: b2007117@hotmail.com.

DOI: $10.4187 /$ respcare.01418 duces severe pulmonary vascular disease and pulmonary arterial hypertension (PAH), and finally results in reversal of the direction of shunting and development of cyanosis (Fig. 1). ${ }^{1}$ The structural abnormalities of the lung circulation are histologically similar to those seen in other forms of PAH. ${ }^{2}$ Eisenmenger syndrome is a multisystem disorder associated with numerous life-threatening complications, including hemoptysis, cerebrovascular accidents, brain abscesses, arrhythmias, and syncope. ${ }^{3}$ Exercise capacity is severely impaired in most patients with Eisenmenger syndrome. Although exercise limitation and exertional dyspnea may remain stable for years, poor exercise capacity identifies the patient at risk for hospitalization or death. ${ }^{4}$

Patients with Eisenmenger syndrome have a reduced life expectancy, even if many can survive into their third or fourth decade. Yet patients with Eisenmenger syndrome fare far better than patients with all other forms of pulmo- 


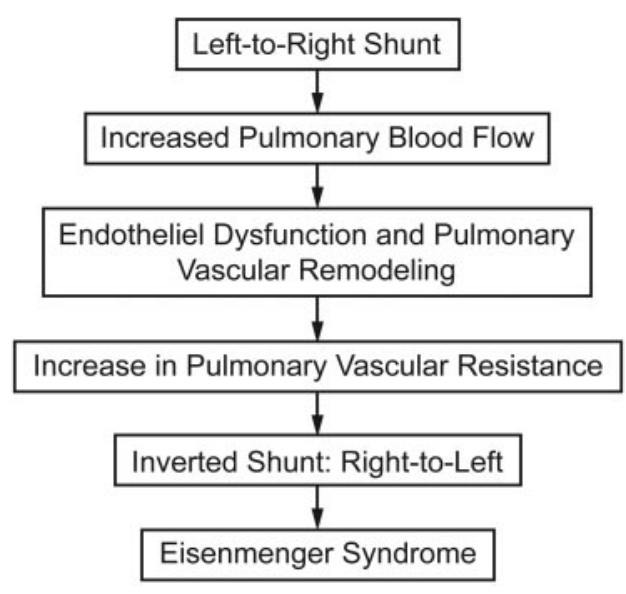

Fig. 1. Key stages in the development of Eisenmenger syndrome.

nary hypertension, a fact that is not appreciated by many who care for such patients. The key to the relative longevity of these complex patients lies in the unique adaptation of the right ventricle..$^{5,6}$

\section{Pathophysiology}

A wide range of cardiac defects can lead to pulmonary vascular disease, although the lesions most common to Eisenmenger syndrome are ventricular septal defects (VSDs), atrial septal defects, atrioventricular septal defects, and patent ductus arteriosus. ${ }^{78}$ Approximately 50\% of all patients with large unrepaired VSDs, approximately $10 \%$ of patients with large unrepaired atrial septal defects, and almost all patients with unrepaired truncus arteriosus are at risk of developing Eisenmenger syndrome. ${ }^{910}$ The underlying defect in Eisenmenger syndrome is important because it has prognostic implications. Evidence suggests, for example, that patients with atrial septal defects differ in their evolution of pulmonary vascular disease, compared with patients with VSDs. ${ }^{8}$ Patients with Eisenmenger syndrome may present with more complex underlying lesions such as truncus arteriosus, transposition of great vessels and VSD, or single ventricles with unobstructed pulmonary blood flow. The development of Eisenmenger syndrome in patients with complex congenital heart disease is associated with a 10-12-fold increase in mortality. ${ }^{10}$

The pathogenesis of PAH involves 3 major processes that contribute to narrowing of the pulmonary artery. The first, vasoconstriction, occurs as a result of an imbalance between vasodilators and vasoconstrictors in the pulmonary circulation. Vascular smooth muscle and endothelial cell proliferation result in vascular remodeling. Finally, coagulation abnormalities result in thrombosis in situ, which contributes to elevated pulmonary vascular resistance.

The mechanisms underlying the remodeling of the cardiopulmonary circulation have not been fully elucidated, but are likely to involve vasoconstriction, inflammation, thrombosis, cell proliferation, and fibrosis. ${ }^{11}$ Implicated in these mechanisms is an errant expression of vasoactive mediators, including endothelin-1, thromboxane, prostacyclin, and nitric oxide. ${ }^{11}$ The remodeled pulmonary arteries in PAH are characterized by vasoconstriction, suppressed apoptosis, and increased proliferation within the vascular wall. In addition to other factors, cytoplasmic $\mathrm{Ca}^{2+}$ in particular seems to play a central role. Vascular remodeling refers to the structural changes that lead to hypertrophy and/or luminal occlusion. ${ }^{12}$ Increased proliferation and hypertrophy of pulmonary arterial smooth muscle cell have been implicated in the development of idiopathic PAH. ${ }^{13}$

\section{Treatment of Eisenmenger Syndrome}

Historically, management options for patients with Eisenmenger syndrome have been limited to palliative measures or heart-lung transplantation, the latter of which is suitable only for a small subgroup of patients. Pharmacologic treatment often involved the use of digitalis, diuretics, anti-arrhythmics, and/or anticoagulants; however, none of these approaches significantly modified survival or risk of deterioration. ${ }^{14,15}$

Research into the underlying pathophysiology of PAH has identified, and continues to identify, several important pathways and mechanisms that are involved in the vascular changes characteristic of the disease, and has led to the development of successful, targeted therapies. Results from clinical trials of these therapies in patients with Eisenmenger syndrome are challenging the notion that it is a stable disease not amenable to treatment. To date, several targeted therapies, including endothelin receptor antagonists, phosphodiesterase type- 5 inhibitors, prostacyclin, and prostacyclin analogs, have shown to be effective in Eisenmenger syndrome patients, offering improvements in exercise capacity, functional class, and hemodynamics, without compromising oxygen saturation. ${ }^{16}$

\section{Corrective Interventions}

Closure of the septal heart defect, either by percutaneous or surgical procedures, is generally contraindicated in adult patients with PAH associated with systemic-topulmonary shunts because of high mortality and poor outcome. ${ }^{14}$ In addition, closure of the defect may take away the "safety valve" in patients with further progression of pulmonary vascular disease and reversal of the pressure gradient between the systemic and pulmonary circulations. The indications for patients to be considered for correction are not uniformly defined and may include pulmonary artery vasoreactivity and/or the presence of a pulmonaryto-systemic flow ratio of at least 1.5 to $1.0 .{ }^{17}$ Furthermore, 
correction of the defect in patients in whom a consistent reduction in PAH is achieved using targeted therapies (the so-called treat-and-repair strategy) remains controversial, and only sporadic case reports have been published. ${ }^{18-21}$

Children diagnosed later in life, who have developed pulmonary vascular disease (resistance exceeding 6 Wood units $/ \mathrm{m}^{2}$ ) and have poor vasodilator response, are at high risk of sustained pulmonary hypertension, right heart failure, and hypertensive crises immediately after surgery. ${ }^{22,23}$ Moreover, right-to-left shunting in the presence of severe PAH sustains cardiac output at the expense of arterial hypoxia. Right-to-left shunting at the atrial level is a mechanism for relieving right atrial pressure in the presence of right ventricular failure. ${ }^{24,25}$ Generally, when right-to-left shunting with cyanosis is present, one has to seriously question the indication for closure. ${ }^{26}$

A recent major breakthrough in the treatment of patients with PAH has been the availability of oral endothelin antagonists (eg, ambrisentan, bosentan, and sitaxsentan) and the applications of sildenafil, a type-5 phosphodiesterase inhibitor. Endothelin antagonists are potent pulmonary vasodilators with limited side effects and a proven beneficial effect when administered to patients with idiopathic PAH (iPAH). In BREATHE 5, a randomized controlled study of bosentan versus placebo, bosentan was effective in reducing pulmonary vascular resistance and improving New York Heart Association functional class ${ }^{16}$ and the 6-min walk test distance in Eisenmenger patients. A major advantage of oral formulations is that they allow long-term administration. Contrary to intravenous targeted therapy requiring continuous infusion (eg, epoprostenol), oral agents are not associated with complications such as line infections, endocarditis, and paradoxical emboli, and do not impose the limitations that continuous intravenous infusion imposes on the quality of life of these patients. Advanced therapies for PAH are now being increasingly used to reduce the risk of developing or treating postoperative PAH in patients prior to and after surgical repair for congenital heart disease or acquired valve disease. ${ }^{27,28}$

Postoperative pulmonary hypertension is, in fact, a major determinant of perioperative morbidity and mortality in patients undergoing cardiac surgery. Pulmonary hypertensive crises are characterized by an acute increase in pulmonary vascular resistance, which precipitates right ventricular failure and causes a drop in cardiac output. Older patients with elevated pulmonary arterial pressure preoperatively are at higher risk of developing postoperative PAH. ${ }^{29,30}$ Advanced PAH therapies might have the potential to produce a reduction in pulmonary vascular resistance, lowering perioperative risks and possibly widening the range of cases amenable to repair.

Eisenmenger syndrome has been synonymous with inoperability, as patients are perceived to have irreversible obstructive pulmonary vascular disease that puts them at high perioperative risk, at low likelihood of benefiting from the procedure, and at high risk of postoperative right ventricular failure. Right-to-left shunting in patients with $\mathrm{PAH}$, in fact, acts as a safety valve and forms the basis of practicing atrial septostomy in patients with $\mathrm{PAH} .{ }^{31-35} \mathrm{Nev}-$ ertheless, despite the established longstanding pulmonary vascular disease with evidence of substantial vascular remodeling/obstruction, Eisenmenger patients often respond favorably to advanced therapy. ${ }^{16}$ It has been demonstrated that almost one third of Eisenmenger patients maintain some degree of pulmonary vasoreactivity despite the presence of obstructive pulmonary hypertension. ${ }^{36}$ Moreover, it has been suggested that endothelin receptor antagonists may have antiproliferative effects causing reverse-remodeling in the pulmonary circulation. ${ }^{16,37}$

Cerebrovascular events (strokes/abscesses) are major, devastating, and debilitating complications of Eisenmenger syndrome, and are directly related to right-to-left shunting. Moreover, cyanosis is a major cause of exercise limitation, triggers erythrocytosis, and is associated with both bleeding diathesis and thrombosis. Systemic arterial desaturation may also aggravate pulmonary vascular obstruction and cause peripheral organ failure. It is, thus, conceivable that abolishing the right-to-left shunt may produce a symptomatic improvement in highly symptomatic patients.

The palliative Mustard procedure is an interesting model of the benefits derived from reduction of hypoxia in patients with PAH secondary to congenital heart disease. In this procedure, patients with transposition of great arteries and a large ventricular communication, in which oxygen saturations in the pulmonary artery are higher than that in the aorta, undergo an atrial switch without VSD closure. ${ }^{38,39}$ The increase in arterial oxygen saturation resulting from redirection of flow provides significant symptomatic relief and increased quality of life in patients with severe cyanosis-related symptoms. It has been suggested that treatment with advanced therapies without correction of the underlying anatomical defect may lead to further insult on the pulmonary circulation. In the case of patients with large VSDs, for example, the drop in pulmonary vascular resistance induced by such therapies leads to an increase in flow and shear stress in the pulmonary circulation, while high pressures through the defect persist. ${ }^{20}$

There is potential conversion of Eisenmenger physiology to iPAH physiology with worse long-term outcome and high perioperative risk, but experience is very limited and no long-term data are available. There are serious concerns when taking into consideration closure of cardiac defects in patients with established PAH. The mainstay of this approach is an effective decrease in pulmonary vascular resistance by advanced therapies, the long-term results and tolerability of which remain unknown. Moreover, no data are available on the long-term response of the right ventricle to closure of intracardiac communica- 
Eisenmenger Syndrome: Not Always Inoperable

Table 1. Available Data on Closure of Cardiac Communications in the Presence of Severe Pulmonary Arterial Hypertension

\begin{tabular}{|c|c|c|c|c|c|c|c|c|}
\hline \multirow{2}{*}{ First Author } & \multirow{2}{*}{$\begin{array}{c}\text { Year } \\
\text { Published }\end{array}$} & \multirow{2}{*}{$\begin{array}{l}\text { Age } \\
\text { (y) }\end{array}$} & \multirow{2}{*}{ Type } & \multirow{2}{*}{$\begin{array}{l}\text { NYHA } \\
\text { Class }\end{array}$} & \multirow{2}{*}{$\begin{array}{l}\text { Baseline } \\
\text { MPAP } \\
(\mathrm{mm} \mathrm{Hg})\end{array}$} & \multirow{2}{*}{ Medication } & \multicolumn{2}{|c|}{ Improvement } \\
\hline & & & & & & & Clinical & Hemodynamic \\
\hline Schwerzmann $^{19}$ & 2006 & 38 & ASD & III & 53 & $\mathrm{PGI}_{2}, 12 \mathrm{mo}$ & Yes & Yes \\
\hline Yamauchi $^{43}$ & 2001 & 35 & ASD & II & 65 & $\mathrm{PGI}_{2}, 24 \mathrm{mo}$ & Yes & Yes \\
\hline Frost $^{18}$ & 2005 & 29 & ASD & III & 60 & $\mathrm{PGI}_{2}, 48 \mathrm{mo}$ & Yes & Yes \\
\hline Imanaka $^{44}$ & 1998 & 51 & ASD & & 53 & Nitric oxide & Yes & Yes \\
\hline Eicken $^{20}$ & 2007 & 35 & PDA & III & 66 & Bosentan, 5 mo & Yes & Yes \\
\hline \multicolumn{9}{|c|}{$\begin{array}{l}\text { NYHA }=\text { New York Heart Association } \\
\text { MPAP }=\text { mean pulmonary artery pressure } \\
\text { ASD }=\text { atrial septal defect } \\
\text { PGI }_{2}=\text { prostacyclin } \\
\text { PDA }=\text { patent ductus arteriosus }\end{array}$} \\
\hline
\end{tabular}

tions in patients with right-to-left shunting. Once the defect is closed, a pathophysiologic situation more similar to iPAH could become established, which is associated with a much worse long-term outcome, compared to Eisenmenger patients. It has been hypothesized that the striking difference in outcome between Eisenmenger and iPAH patients is due to the presence of the defect, which permits unloading of the right ventricle by means of right-to-left shunting and thus preservation of right ventricular function. Thus, closure of the defect without marked reduction of pulmonary arterial pressure and abolition of the rightto-left shunt could alter the natural history of Eisenmenger syndrome to resemble that of iPAH.

It is, nevertheless, important to remember that, different from iPAH, the pulmonary circulation of a child who develops PAH due to congenital heart disease does not grow normally. ${ }^{40}$ In fact, intra-acinar arteries are reduced, and endothelial dysfunction and smooth muscle cell hyperplasia are present early after birth. Therefore, fundamental differences in pathophysiology are likely to be present in Eisenmenger and $\mathrm{PAH}$ patients.

An additional reason for concern when contemplating surgery in patients with PAH is the high perioperative risk. Hypertensive crises can be triggered by hypoxia, acidosis, and cardiopulmonary bypass itself. ${ }^{41,42}$ Moreover, endotracheal suctioning causes sympathetic stimulation and substantial rise in pulmonary vascular resistance, which can be attenuated by adequate pretreatment with high doses of narcotics. ${ }^{43}$ Postoperative ventilation/perfusion mismatch may result in alveolar hypoxia and trigger vasoconstriction. ${ }^{42}$

Available data on closure of intra- or extracardiac communications in the presence of severe $\mathrm{PAH}$, with or without the use of advanced therapies, are scarce and still limited to case reports (Table 1).43-57 Closure of intracardiac defects after a positive response to advanced $\mathrm{PAH}$ therapies cannot therefore be generally recommended until hard evidence of its safety, efficacy, and durability be- comes available. An essential step to adopting a treat-andrepair approach will be the appropriate selection of patients who may benefit from it. Patients with less advanced pulmonary vascular disease and those who demonstrate a substantial response to advanced therapy are likely to be considered. In all cases, careful assessment of the balance between the benefit of closing a large defect and abolishing the shunt (and cyanosis if present) and the risk of causing deterioration of right ventricular function and diminishing systemic cardiac output should be performed. ${ }^{48}$ Certainly, formal hemodynamic assessment with vasoreactivity testing is important, as patients with lower preoperative pulmonary vascular resistance and evidence of substantial vasoreactivity are likely to be better candidates. Defect closure in patients with PAH should be undertaken only if the benefits of abolishing the shunt outweigh the risks of surgical or percutaneous closure. Nevertheless, regardless of the closure technique, should restoration of the communication become necessary in patients who develop right ventricular failure or low cardiac output post closure, this may be difficult and carry additional risk to the patient.

Response to advanced therapy is another important issue that needs to be addressed. There is no uniform response to advanced therapy, as some patients demonstrate strong benefit, whereas others may show little or no response. Pretreatment with advanced therapies for a sufficient period of time to assess the hemodynamic and symptomatic response and tolerance to long-term administration is, thus, strongly recommended before closure is undertaken. Partial closure of a defect with a one-way flap that permits right-to-left shunting could be a way of allowing decompression of the right ventricle during periods of raised pulmonary vascular resistance, especially in the postoperative period, while limiting flow and pressure stress to the pulmonary circulation. ${ }^{49}$ Subsequent complete closure of the defect could be performed should pulmonary vascular resistance fall in response to longer term advanced ther- 


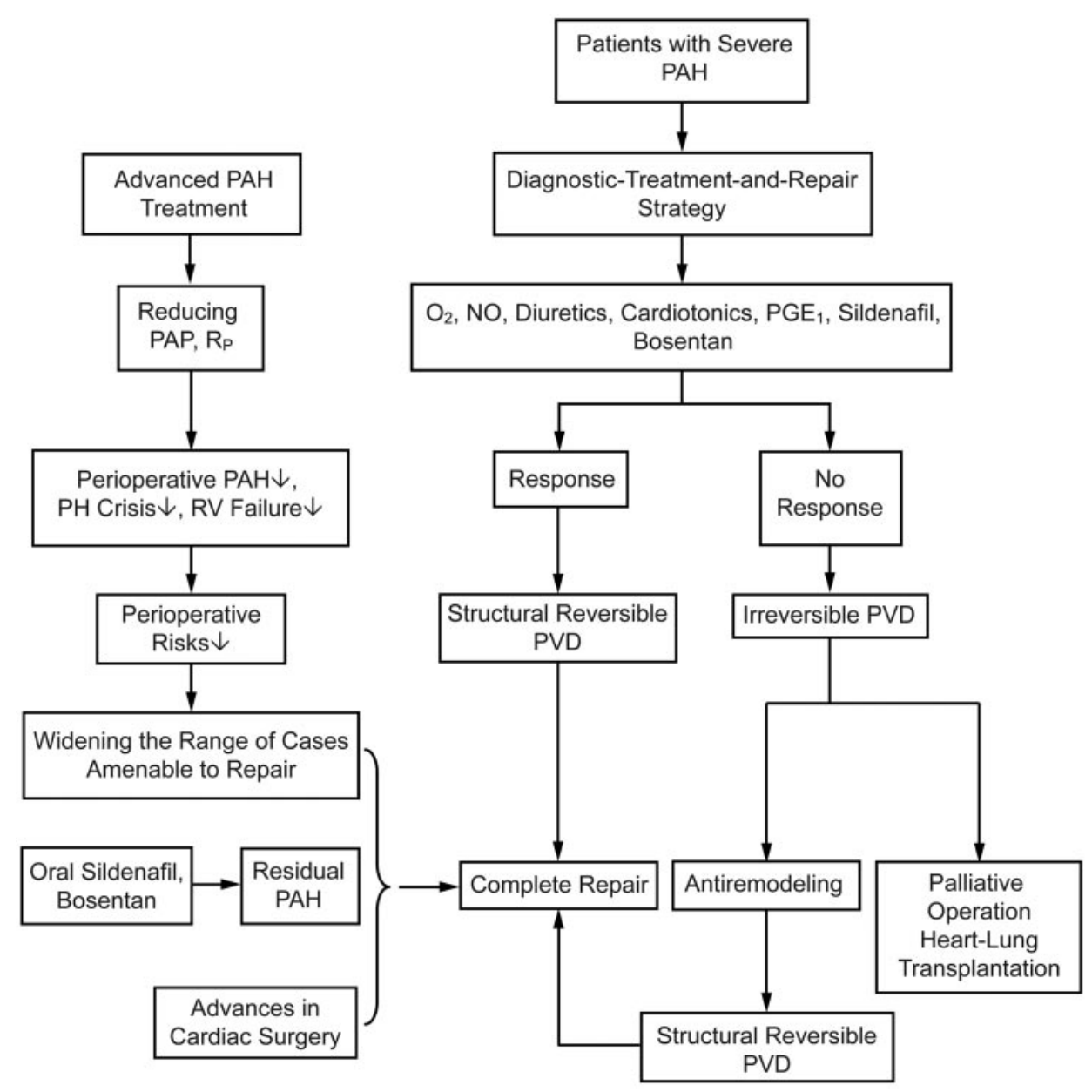

Fig. 2. Diagnostic-treatment-and-repair strategy for pulmonary arterial hypertension (PAH). PAP = pulmonary arterial pressure. Rp = pulmonary vascular resistance. $\mathrm{NO}=$ nitric oxide. $\mathrm{PGE} 1=$ prostaglandin $\mathrm{E} 1 . \mathrm{PH}=$ pulmonary hypertension. $\mathrm{RV}=$ right ventricle. $\mathrm{PVD}=$ pulmonary vascular disease.

apy. Another staged approach could be the application of a pulmonary arterial band once pulmonary vascular resistance starts to decrease in response to chronic advanced therapy. ${ }^{50}$ Should pulmonary vascular resistance decrease further, closure of the defect with debanding could follow. Finally, whether closure of a post tricuspid defect (VSD or patent ductus arteriosus), while allowing or creating an atrial communication and thus the potential of right-to-left shunting, could convene any hemodynamic, symptomatic, or prognostic benefit remains purely speculative.

The key problem of operability of Eisenmenger syndrome is evaluating whether pulmonary hypertension is reversible. In the study reported by Liu and colleagues, negative inhaled oxygen test did not necessarily mean irreversibility. Inhaled oxygen test was negative in $68.7 \%$ (33/48) with regression of PAH after successful surgical correction. Patients with severe PAH received diagnostic treatment preoperatively, with advanced $\mathrm{PAH}$ treatment (nitric oxide continuously inhaled, sildenafil, and bosen$\tan )$. Advanced PAH treatment generally lasts 2 weeks, the patient who received a diagnostic treatment and whose transcutaneous oxygen saturation increased at least 5\% was deemed to adequately respond and underwent complete repair; otherwise the patient who did not respond (whose transcutaneous oxygen saturation increased less than $5 \%$ ) was excluded from the operation. Eight percent (4/50) were excluded from the operation because PAH was not shown to be reversible. Lung biopsy study also confirmed that diagnostic-treatment-and-repair strategy is an effective method to determine whether PAH is reversible. Of 11 patients who received diagnostic treatment, only $1(1 / 11)$ showed grade IV change with plexiform lesion, and follow-up data showed the reversal of PAH of all the patients. Preoperative diagnostic treatment also improved the general condition of patients with severe PAH and tolerability to surgery and decreased perioperative risks. One patient died of PAH crisis. Four patients refractory to conventional therapies with residual PAH were given oral sildenafil or bosentan for the long-term, and good results were also attained. ${ }^{56,57}$ 
Table 2. Speculative Therapeutic Options for Pulmonary Arterial Hypertension

\begin{tabular}{llll}
\hline \multicolumn{1}{c}{ Drug } & Administration & Adverse effects \\
Rasudil & Intravenous & Dosage & Flushing \\
Imatinib & Oral & $30 \mathrm{mg}$ for $30 \mathrm{~min}$ & Cardiotoxicity \\
Simvastatin & Oral & $200 \mathrm{mg}$ once a day & Myalgias \\
Ghrelin & Unknown & $20-80 \mathrm{mg}$ once a day & Unknown \\
Bradykinin & Unknown & Unknown & Unknown \\
Fluoxetine & Oral & Unknown & Mild gastrointestinal symptoms \\
Dichloroacetate & Oral & Unknown & Unknown \\
Vasoactive intestinal peptide & Inhalation & Unknown & Unknown \\
\hline
\end{tabular}

Liu and colleagues discussed the mechanisms of repair of patients with severe pulmonary hypertension. Postoperative PAH was a statistically significant independent predictor of operative mortality. It is important to decrease postoperative PAH for increased operative survival (Fig. 2). The following factors contribute to the operability of these selected patients: pulmonary vascular disease is structurally reversible; advanced therapies for PAH have been available and effective in reducing pulmonary vascular resistance in patients with severe $\mathrm{PAH}$; oral endothelin antagonists and the applications of sildenafil allow longterm administration; and advances in cardiac surgery contribute to the safety and efficacy of the repair of these selective patients. Figure 2 shows the mechanisms of repair of patients with severe $\mathrm{PH}$ in the current era. $56,57,58$ Older patients with severe PAH are at higher risk of developing postoperative PAH. The incidence of postoperative PAH was $57 \%$ (49/86). Postoperative PAH is, in fact, a major determinant of perioperative morbidity and mortality. Advanced PAH therapies combined with the advances of cardiac surgery might have the potential to produce a reduction in pulmonary vascular resistance, lowering perioperative risks and widening the range of cases amenable to repair.

In the study reported by Huang and colleagues, transcutaneous oxygen saturation of all patients who underwent radical repair selected by diagnostic-treatment-and-repair strategy increased significantly, from pre-diagnostic treatment $87.5 \pm 8.2 \%$ to post-diagnostic treatment $95.8 \pm 5.6 \%$ $(P<.001)$. There were no operative deaths. Mean pulmonary artery pressure regressed significantly, from preoperative $69.4 \pm 11.6 \mathrm{~mm} \mathrm{Hg}$ to postoperative $30.8 \pm 11.0 \mathrm{~mm} \mathrm{Hg}$ $(P<.001)$, and pulmonary vascular resistance also regressed significantly, from preoperative 1,640.8 $\pm 712.2 \mathrm{dyn} /$ $\mathrm{s} / \mathrm{cm}$ to postoperative $736.1 \pm 290.4 \mathrm{dyn} / \mathrm{s} / \mathrm{cm}(P<.001)$. Of 49 patients, mean pulmonary artery pressure of $20 \mathrm{~mm} \mathrm{Hg} \mathrm{(20/49} \mathrm{mm} \mathrm{Hg)} \mathrm{regressed} \mathrm{to} \mathrm{normal} \mathrm{postoper-}$ atively. The incidence of postoperative PAH was $59.2 \%$ (29/49), mild PAH (mean pulmonary artery pressure 25$30 \mathrm{~mm} \mathrm{Hg}$ ) $14.3 \%$ (7/49), moderate PAH (mean pulmonary artery pressure $30-50 \mathrm{~mm} \mathrm{Hg}$ ) $36.7 \%$ (18/49), severe
PAH (mean pulmonary artery pressure $>50 \mathrm{~mm} \mathrm{Hg}$ ) $8.2 \%$ (4/49). All patients were administered drugs for PAH. All patients recovered well and were discharged. The pulmonary vascular disease in these selected patients with congenital heart disease and severe $\mathrm{PAH}$, using a diagnostic-treatment-and-repair strategy, is generally reversible and these patients are operable with safety and efficacy in the current era with advanced PAH therapy. The long-term benefits of radical repair for these selected patients with congenital heart disease and severe PAH need to be demonstrated with a larger number of patients and longer follow-up. ${ }^{56-59}$

\section{Future Directions}

PAH is now considered to be a proliferative disorder characterized by unexplained proliferation of pulmonary arterial smooth muscle cell and pulmonary artery endothelial cells. The focus of treatment of PAH is turning to strategies for inhibiting vascular proliferation and promoting vascular apoptosis to reverse pulmonary vascular remodeling. Anti-remodeling treatment is becoming a potential therapeutic option against various types of PAH. Inhibition of pulmonary arterial smooth muscle cell growth and augmentation of cell apoptosis could serve as therapeutic approaches for patients with PAH. ${ }^{60-62}$ A summary of all novel, emerging therapies examined here can be found in Table 2.63-66 Future directions may be the combination of reversal of pulmonary vascular remodeling and correction.

\section{Conclusions}

With continued improvements in the diagnosis, preoperative management, refinement of surgical techniques and intra- and postoperative management strategies, patients with Eisenmenger syndrome might be amenable to and benefit from repair in the current era. Future directions may be the combination of reversal of pulmonary vascular remodeling and correction. 


\section{REFERENCES}

1. Berman EB, Barst RJ. Eisenmenger's syndrome: current management. Prog Cardiovasc Dis 2002;45(2):129-138.

2. Deanfield J, Thaulow E, Warnes C, Webb G, Kolbel F, Hoffman A, et al. Management of grown up congenital heart disease. Eur Heart J 2003;24(11):1035-1084.

3. Vongpatanasin W, Brickner ME, Hillis LD, Lange RA. The Eisenmenger syndrome in adults. Ann Intern Med 1998;128(9):745-755.

4. Pietra GG, Capron F, Stewart S, Leone O, Humber DM, Reid L, et al. Pathologic assessment of vasculopathies in pulmonary hypertension. J Am Coll Cardiol 2004;43(Suppl 1):S25-S32.

5. Daliento L, Somerville J, Presbitero P, Menti L, Brach-Prever S, Rizzoli G, et al. Eisenmenger syndrome: factors relating to deterioration and death. Eur Heart J 1998;19(12):1845-1855.

6. Diller GP, Dimopoulos K, Okonko D, Li W, Babu-Narayan SV, Broberg CS, et al. Exercise intolerance in adult congenital heart disease: comparative severity, correlates, and prognostic implication. Circulation 2005;112(6):828-835.

7. Wood P. The Eisenmenger syndrome or pulmonary hypertension with reversed central shunt. BMJ 1958;2(5098):701-709.

8. Diller GP, Gatzoulis MA. Pulmonary vascular disease in adults with congenital heart disease. Circulation 2007;115(8):1039-1050.

9. Vongpatanasin W, Brickner ME, Hillis LD, Lange RA. The Eisenmenger syndrome in adults. Ann Intern Med 1998;128(9):745-755.

10. Kidd L, Driscoll DJ, Gersony WM, Hayes CJ, Keane JF, O'Fallon WM, et al. Second natural history study of congenital heart defects. Results of treatment of patients with ventricular septal defects. Circulation 1993;87(2 Suppl):I38-I51.

11. Humbert M, Morrell NW, Archer SL, Stenmark KR, MacLean MR, Lang IM, et al. Cellular and molecular pathobiology of pulmonary arterial hypertension. J Am Coll Cardiol 2004;43(Suppl S):13S-24S.

12. Bonnet S, Rochefort G, Sutendra G, Archer SL, Haromy A, Webster $\mathrm{L}$, et al. The nuclear factor of activated $\mathrm{T}$ cells in pulmonary arterial hypertension can be therapeutically targeted. Proc Natl Acad Sci U S A 2007;104(27):11418-11423.

13. Yuan JX, Rubin LJ Thaulow E. Pathophysiology of pulmonary arterial hypertension. In: Scharf SM, editor. Respiratory-circulatory interactions in health and disease. New York: Marcel Dekker; 2001: 447-477.

14. Deanfield J, Thaulow E, Warnes C, Webb G, Kolbel F, Hoffman A, et al. Management of grown congenital heart disease. Eur Heart $\mathbf{J}$ 2003;24(11):1035-1084.

15. Beghetti, M, Galiè N. Eisenmenger syndrome, a clinical perspective in a new therapeutic era of pulmonary arterial hypertension. J Am Coll Cardiol 2009;53(9):733-740.

16. Galiè N, Beghetti M, Gatzoulis MA, Granton J, Berger RM, Lauer A, et al. Bosentan therapy in patients with Eisenmenger syndrome: a multicenter, double-blind, randomized, placebo-controlled study. Circulation 2006;114(1):48-54.

17. Therrien J, Warnes C, Daliento L, Hess J, Hoffmann A, Marelli A, et al. Canadian Cardiovascular Society Consensus Conference 2001 update: recommendations for the management of adults with congenital heart disease part III. Can J Cardiol 2001;17(11):1135-1158.

18. Frost AE, Quiñones MA, Zoghbi WA, Noon GP. Reversal of pulmonary hypertension and subsequent repair of atrial septal defect after treatment with continuous intravenous epoprostenol. J Heart Lung Transplant 2005;24(4):501-503.

19. Schwerzmann M, Zafar M, McLaughlin PR, Chamberlain DW, Webb G, Granton J. Atrial septal defect closure in a patient with 'irreversible' pulmonary hypertensive arteriopathy. Int J Cardiol 2006; 110(1):104-107.

20. Eicken A, Balling G, Gildein HP, Genz T, Kaemmerer H, Hess J. Transcatheter closure of a non-restrictive patent ductus arteriosus with an Amplatzer muscular ventricular septal defect occluder. Int J Cardiol 2007;117(1):e40-e42.

21. Dimopoulos K, Peset A, Gatzouulis MA. Evaluating operability in adults with congenital heart disease and the role of pretreatment with targeted pulmonary arterial hypertension therapy. Int J Cardiol 2008; 129(2):163-171.

22. Beghetti M. Pulmonary arterial hypertension related to congenital heart disease. Munich: Elsevier; 2006.

23. Moss AJ, Adams FH, Emmanouilides GC, Riemenschneider TA. Moss' heart disease in infants, children and adolescents. Baltimore: Lippincott Williams \& Wilkins; 1989.

24. Marie Valente A, Rhodes JF. Current indications and contraindications for transcatheter atrial septal defect and patent foramen ovale device closure. Am Heart J 2007;153(4 Suppl):81-84.

25. Allcock RJ, O'Sullivan JJ, Corris PA. Atrial septostomy for pulmonary arterial hypertension. Heart 2003;89(11):1344-1347.

26. Webb G, Gatzoulis MA. Atrial septal defects in the adult: recent progress and overview. Circulation 2006;114(15):1645-1653.

27. Trachte AL, Lobato EB, Urdaneta F, Hess PJ, Klodell CT, Martin TD, et al. Oral sildenafil reduces pulmonary hypertension after cardiac surgery. Ann Thorac Surg 2005;79(1):194-197.

28. Ikonomidis JS, Hilton EJ, Payne K, Harrell A, Finklea L, Clark L, et al. Selective endothelin-A receptor inhibition after cardiac surgery: a safety and feasibility study. Ann Thorac Surg 2007;83(6): 2153-2160

29. Miller OI, Tang SF, Keech A, Pigott NB, Beller E, Celermajer DS. Inhaled nitric oxide and prevention of pulmonary hypertension after congenital heart surgery: a randomised double-blind study. Lancet 2000;356(9240): 1464-1469.

30. Bando K, Turrentine MW, Sharp TG, Sekine Y, Aufiero TX, Sun K, et al. Pulmonary hypertension after operations for congenital heart disease: analysis of risk factors and management. J Thorac Cardiovasc Surg 1996;112(6):1600-1609.

31. Kerstein D, Levy PS, Hsu DT, Hordof AJ, Gersony WM, Barst RJ. Blade balloon atrial septostomy in patients with severe primary pulmonary hypertension. Circulation 1995;91(7):2028-2035.

32. Klepetko W, Mayer E, Sandoval J, Trulock EP, Vachiery JL, Dartevelle $\mathrm{P}$, et al. Interventional and surgical modalities of treatment for pulmonary arterial hypertension. J Am Coll Cardiol 2004;43 (12 Suppl S):73S-80S.

33. Micheletti A, Hislop AA, Lammers A, Bonhoeffer P, Derrick G, Rees P, et al. Role of atrial septostomy in the treatment of children with pulmonary arterial hypertension. Heart 2006;92(7):969-972.

34. Tapson V. Atrial septostomy: why we still need it. Chest 2007; 131(4):947-948.

35. Kurzyna M, Dabrowski M, Bielecki D, et al. Atrial septostomy in treatment of end-stage right heart failure in patients with pulmonary hypertension. Chest 2007;131(4):977-983.

36. Budts W, Van Pelt N, Gillyns H, Gewillig M, Van de Werf F, Janssens S. Residual pulmonary vasoreactivity to inhaled nitric oxide in patients with severe obstructive pulmonary hypertension and Eisenmenger syndrome. Heart 2001;86(5):553-558.

37. Humbert M, Sitbon O, Simonneau G. Treatment of pulmonary arterial hypertension. N Engl J Med 2004;351(14):1425-1436.

38. Bernhard WF, Dick IIM, Sloss LJ, Castaneda AR, Nadas AS. The palliative Mustard operation for double outlet right ventricle or transposition of the great arteries associated with ventricular septal defect, pulmonary arterial hypertension, and pulmonary vascular obstructive disease. A report of eight patients. Circulation 1976;54(5):810-817.

39. Burkhart HM, Dearani JA, Williams WG, Puga FJ, Mair DD, Ashburn DA, et al. Late results of palliative atrial switch for transposition, ventricular septal defect, and pulmonary vascular obstructive disease. Ann Thorac Surg 2004;77(2):464-469. 
40. Hall SM, Haworth SG. Onset and evolution of pulmonary vascular disease in young children: abnormal postnatal remodelling studied in lung biopsies. J Pathol 1992;166(2):183-193.

41. Verrier ED, Boyle EM Jr. Endothelial cell injury in cardiovascular surgery. Ann Thorac Surg 1996;62(3):915-922.

42. Hopkins RA, Bull C, Haworth SG, de Leval MR, Stark J. Pulmonary hypertensive crises following surgery for congenital heart defects in young children. Eur J Cardiothorac Surg 1991;5(12):628-34.

43. Yamauchi H, Yamaki S, Fujii M, Iwaki H, Tanaka S. Reduction in recalcitrant pulmonary hypertension after operation for atrial septal defect. Ann Thorac Surg 2001;72(3):905-906.

44. Imanaka K, Kotsuka Y, Takamoto S, Furuse A, Inoue K, Shirai T. Atrial septal defect and severe pulmonary hypertension in an adult who needed nitric oxide inhalation after repair. Kyobu Geka 1998; 51(5):403-405. Article in Japanese.

45. Hickey PR, Hansen DD, Wessel DL, Lang P, Jonas RA, Elixson EM. Blunting of stress responses in the pulmonary circulation of infants by fentanyl. Anesth Analg 1985;64(12):1137-1142.

46. Mizuhara A, Ino T, Adachi H, Ide H, Yamaguchi A, Kawahito K. Surgical treatment of adult secundum ASD with severe pulmonary hypertension - two case reports. Nippon Kyobu Geka Gakkai Zasshi 1993;41(6):1089-1093. Article in Japanese.

47. Satoh T, Yagi T, Kato S, Azuma K, Kataoka M, Takahashi T, et al. A 38-year-old man with pulmonary hypertension, who had undergone atrial septal closure 26 years previously. Keio J Med 2003; 52(4):250-262.

48. Gatzoulis MA, Freeman MA, Siu SC, Webb GD, Harris L. Atrial arrhythmia after surgical closure of atrial septal defects in adults. N Engl J Med 1999;340(11):839-846.

49. Novick WM, Sandoval N, Lazorhysynets VV, Castillo V, Baskevitch A, Mo X, et al. Flap valve double patch closure of ventricular septal defects in children with increased pulmonary vascular resistance. Ann Thorac Surg 2005;79(1):21-28.

50. Khan SA, Gelb BD, Nguyen KH. Evaluation of pulmonary artery banding in the setting of ventricular septal defects and severely elevated pulmonary vascular resistance. Congenit Heart Dis 2006;1(5): 244-250.

51. Apostolopoulou SC, Papagiannis J, Rammos S. Bosentan induces clinical, exercise and hemodynamic improvement in a pre-transplant patient with plastic bronchitis after Fontan operation. J Heart Lung Transplant 2005;24(8):1174-1176.

52. Khambadkone S, Li J, de Leval MR, Cullen S, Deanfield JE, Redington AN. Basal pulmonary vascular resistance and nitric oxide responsiveness late after Fontan-type operation. Circulation 2003; 107(25):3204-3208.
53. Varma C, Warr MR, Hendler AL, Paul NS, Webb GD, Therrien J. Prevalence of "silent" pulmonary emboli in adults after the Fontan operation. J Am Coll Cardiol 2003;41(12):2252-2258.

54. Takahashi K, Mori Y, Yamamura H, Nakanishi T, Nakazawa M. Effect of beraprost sodium on pulmonary vascular resistance in candidates for a Fontan procedure: a preliminary study. Pediatr Int 2003; 45(6):671-675.

55. Nemoto $\mathrm{S}$, Umehara E, Ikeda T, Itonaga T, Komeda M. Oral sildenafil ameliorates impaired pulmonary circulation early after bidirectional cavopulmonary shunt. Ann Thorac Surg 2007;83(5):E11-E13.

56. Liu YL, Hu SS, Shen XD, Li SJ, Wang X, Yan J, et al. Midterm results of arterial switch operation in older patients with severe pulmonary hypertension. Ann Thorac Surg 2010;90(3):848-855.

57. Huang JB, Liu YL, Yu CT, Lv XD, Du M, Wang Q, et al. Lung biopsy findings in previously inoperable patients with severe pulmonary hypertension associated with congenital heart disease. Int J Cardiol 2011;151(1):76-83.

58. Liu YL, Hu SS, Shen XD, Li SJ, Wang X, Yan J, et al. Safety and efficacy of arterial switch operation in previously inoperable patients. J Card Surg 2010;25(4):400-405.

59. Epting CL, Wolfe RR, Abman SH, Deutsch GH, Ivy D. Reversal of Pulmonary Hypertension Associated with Plexiform Lesions in Congenital Heart Disease: A Case Report. Pediatr Cardiol 2002; 23(2): 182-185.

60. Rai PR, Cool CD, King JA, Stevens T, Burns N, Winn RA, et al. The cancer paradigm of severe pulmonary arterial hypertension. Am J Respir Crit Care Med 2008;178(6):558-564.

61. Ali O, Wharton J, Gibbs JS, Howard L, Wilkins MR. Emerging therapies for pulmonary arterial hypertension. Expert Opin Investig Drugs 2007;16(6):803-818.

62. Huang JB, Liu YL, Lv XD. Pathogenic mechanisms of congenital heart disease. Fetal Pediatr Pathol 2010;29(5):359-372.

63. Huang JB, Liu YL, Sun PW, Lv XD, Bo K, Fan XM. Novel strategy for treatment of pulmonary hypertension: enhancement of apoptosis. Lung 2010;188(3):179-189.

64. Jing-Bin H, Ying-Long L, Pei-Wu S, Xiao-Dong L, Ming D, XiangMing F. Molecular mechanisms of congenital heart disease. Cardiovasc Pathol 2010;19(5):e183-e193.

65. Chen G, Huang JB, Mi J, He YF, Wu XH, Luo CL, et al. Characterization of acute renal allograft rejection by proteomic analysis of renal tissue in rat. Mol Biol Rep 2012;39(2):1315-1322. DOI: 10. 1007/s11033-011-0864-5.

66. Emin G, Xiao S. The key role of apoptosis in the pathogenesis and treatment of pulmonary hypertension. Eur J Cardiothorac Surg 2006; 30(3):499-507. 